DOI: http://dx.doi.org/10.18203/2320-1770.ijrcog20174129

Original Research Article

\title{
Clinical outcomes of ectopic pregnancy
}

\section{Roopa Malik*, Shaveta Jain, Nirmala Duhan, Daya Sirohiwal}

Department of Obstetrics and Gynecology, PGIMS Rohtak, Haryana, India

Received: 09 August 2017

Accepted: 24 August 2017

\author{
*Correspondence: \\ Dr. Roopa Malik, \\ E-mail: drroopa.sangwan@gmail.com
}

Copyright: (C) the author(s), publisher and licensee Medip Academy. This is an open-access article distributed under the terms of the Creative Commons Attribution Non-Commercial License, which permits unrestricted non-commercial use, distribution, and reproduction in any medium, provided the original work is properly cited.

\begin{abstract}
Background: Ectopic pregnancy (EP) is a life threatening gynaecological emergency, and a significant cause of maternal mortality and morbidity worldwide. Aim of this study was to determine and evaluate the incidence, clinical presentation, risk factors, management strategies and outcome of the patients with EP.

Methods: This was a prospective study of all cases of ectopic pregnancies admitted and managed at PGIMS Rohtak over a period of 1 year. All patients admitted through accident and emergency unit as well as the gynaecology clinic that were managed in gynaecological ward were included in the study. The diagnosis of EP was made by history, clinical examination, urinary pregnancy test and ultrasound examination. Patients were managed as per hospital protocol and relevant data on age, parity, clinical presentation, risk factors, management and findings at laparotomy, and the outcome of treatment were collected.

Results: The incidence of ectopic pregnancy in this study was $1.056 \%$. The mean age of the patients was $27 \pm 3$ years. Of the 102 ectopic pregnancies, $86(84.31 \%)$ were ruptured ectopic pregnancies, while $16(15.68 \%)$ were unruptured ectopic pregnancies. The commonest clinical complaint was abdominal pain (97 of 102, 95.09\%) History of previous abortion (induced or spontaneous) was the commonest risk factor (92 of 102, 90.19\%) followed by past history of pelvic inflammatory disease (56 of 102, 54.90\%). History of tubal surgery was present in 27 of 102 patients $(26.47 \%)$. commonest surgical procedure done was emergency laparotomy followed by salpingectomy (67 of 102, 65.68\%).

Conclusions: EP is an important cause of maternal morbidity and mortality in early pregnancy and has remained a reproductive health challenge. Early diagnosis and treatment can improve reproductive outcomes.
\end{abstract}

Keywords: Ectopic pregnancy, Life- threatening, Pregnancy, Saplingectomy, Salpingostomy

\section{INTRODUCTION}

Ectopic pregnancy (EP) refers to implantation of fertilized ovum outside endometrial cavity. It remains an important cause of maternal mortality and morbidity in developing nations. The reported incidence in literature is $1.5-2.0 \%$ of all pregnancies but varies significantly among countries. ${ }^{1}$ When ruptured EP is true medical emergency. It is a leading cause of maternal mortality in the first trimester of pregnancy and accounts for $10-15 \%$ of all maternal deaths. ${ }^{2}$ It is also a cause of fetal wastage and has been associated with recurrence and impairement of future fertility. ${ }^{3}$

With increase in in vitro fertilization, incidence of EP is on rise to the tune of 2.5-5-fold. ${ }^{4,5}$ Other important risk factors being previous history of EP, previous tubal surgery, pelvic inflammatory disease, puerperal sepsis, post abortal sepsis, usage of IUCD and progesterone only pills, exposure to diethylstilbisterol in utero and cigarette smoking. However, ectopic pregnancy can occur without any obvious risk factors also. ${ }^{6-8}$ 
Key to proper management of EP needs early diagnosis, resuscitation, timely treatment, and follow-up. Early diagnosis of EP is difficult and needs high index of suspicion by treating physician. Since EP is a major health problem in reproductive age women, the present study was conducted to determine incidence and clinical profile of patients presenting with EP.

\section{METHODS}

This was a prospective study of all cases of ectopic pregnancies admitted and managed at PGIMS Rohtak over a period of 1 year. All patients admitted through accident and emergency unit as well as the gynaecology clinic that were managed in gynaecological ward were included in the study.

A thorough history, clinical examination and urinary pregnancy testing was done in all patients suspected of ectopic pregnancy. Culdocentesis was done in suspected cases of ruptured ectopic pregnancy. Transvaginal ultrasound examination was done in stable patients presenting with adenexal mass and biochemical pregnancy to localize gestational sac, size of ectopic mass, presence of cardiac activity and any evidence of free fluid in pouch of douglas. The diagnosis of ectopic pregnancy was made by history, clinical examination, urine pregnancy test, culdocentesis and ultrasound examination. Patients were managed as per hospital protocol and followed till discharge from the hospital. Relevant data on age, parity, clinical presentation, risk factors, management and findings at laparotomy, need for blood transfusion and postoperative complications were collected using data-entry forms designed for this purpose.

Total number of live births during the study period was collected from labour ward record books.

Data were analysed using SPSS version 20.0 and involved descriptive analysis.

\section{RESULTS}

Over 1-year period there were 9659 deliveries with 102 cases of ectopic pregnancies. The incidence of ectopic pregnancy in this study was $1.056 \%$ (102 of 9,659). The mean age of the patients was $27 \pm 3$ years. Of the 102 ectopic pregnancies, $86(84.31 \%)$ were ruptured ectopic pregnancies, while $16(15.68 \%)$ were unruptured ectopic pregnancies. Table 1 depicts the demographic profile of patients; the majority of patients were within 20-24 years age group. $16(15.68 \%)$ were nulliparous while only 2 $(1.96 \%)$ were grand multiparous.

The clinical presentation of patients is shown in Table 2 . The commonest clinical complaint was abdominal pain (97 of 102, 95.09\%), while amenorrhoea was present in 82 of $102,(80.39 \%)$ patients only. Majority of patients who presented with amenorrhoea had gestation $\leq 8$ weeks.
Site of EP is depicted in Table 3. Only 2 patients of cornual pregnancy and 2 patients of broad ligament pregnancy presented with period of gestation 10-12 weeks. One patient of rudimentary horn pregnancy presented at 18 weeks of gestation. The commonest site of ectopic gestation was ampullary region of fallopian tube (60 of 102, 58.82\%) and the least common site was scar pregnancy and rudimentary horn pregnancy (1 patient each).

Table 1: Demographic characteristic of patients with ectopic pregnancy.

\begin{tabular}{|lll|}
\hline Age (years) & Number $(\mathrm{n}=102)$ & $\%$ \\
\hline$<20$ & 2 & 1.96 \\
\hline $20-24$ & 60 & 58.82 \\
\hline $25-29$ & 27 & 26.47 \\
\hline $30-34$ & 12 & 11.76 \\
\hline $35-39$ & 1 & 0.98 \\
\hline 40 and above & 0 & 0 \\
\hline Parity & & \\
\hline 0 & 16 & 15.68 \\
\hline 1 & 23 & 22.54 \\
\hline 2 & 37 & 36.27 \\
\hline 3 & 16 & 15.68 \\
\hline 4 & 8 & 7.84 \\
\hline 5 and above & 2 & 1.96 \\
\hline
\end{tabular}

Table 2: Clinical presentation of patients with ectopic pregnancy.

\begin{tabular}{|lll|}
\hline Presentation & Number & $\%$ \\
\hline Abdominal pain & 97 & 95.09 \\
\hline Amenorrhea & 82 & 80.39 \\
\hline Vaginal bleeding & 54 & 52.94 \\
\hline Fainting attack/dizziness & 84 & 82.35 \\
\hline Shock & 24 & 23.52 \\
\hline Shoulder tip pain & 15 & 14.70 \\
\hline Diarrhoea & 4 & 3.92 \\
\hline
\end{tabular}

Table 3: Site of ectopic pregnancy.

\begin{tabular}{|lll|}
\hline Site & Number & $\%$ \\
\hline Ampulla & 60 & 58.82 \\
\hline Isthmus & 23 & 22.54 \\
\hline Fimbriae & 9 & 8.82 \\
\hline Interstitial/cornual & 2 & 1.96 \\
\hline Tubo-ovarian & 4 & 3.92 \\
\hline Broad ligament & 2 & 1.96 \\
\hline Scar pregnancy & 1 & 0.98 \\
\hline Rudimentary horn pregnancy & 1 & 0.98 \\
\hline Total & 102 & \\
\hline
\end{tabular}

The risk factors associated with EP have been shown in Table 4. History of previous abortion (induced or spontaneous) was the commonest risk factor (92 of 102, $90.19 \%$ ) followed by past history of pelvic inflammatory 
disease (56 of $102,54.90 \%)$. History of tubal surgery was present in 27 of 102 patients $(26.47 \%)$.

\section{Table 4: Risk factors found in patients with ectopic pregnancy.}

\begin{tabular}{|lll|}
\hline Risk factor & Number & P \\
\hline Previous induced abortion & 19 & $18.62 \%$ \\
\hline Pelvic inflammatory disease & 56 & $54.90 \%$ \\
\hline $\begin{array}{l}\text { Previous tubal surgery } \\
\text { Tubectomy }\end{array}$ & 25 & $24.50 \%$ \\
\hline Recanalisation & 2 & $1.96 \%$ \\
\hline Previous spontaneous abortion & 73 & $71.56 \%$ \\
\hline 0 abortions & 25 & $24.50 \%$ \\
\hline 1 abortion & 63 & $61.76 \%$ \\
\hline 2 abortions & 7 & $6.86 \%$ \\
\hline 3 abortions & 2 & $1.96 \%$ \\
\hline 4 abortions & 1 & $0.98 \%$ \\
\hline Puerperal sepsis & 3 & $2.94 \%$ \\
\hline Previous ectopic pregnancy & 3 & $2.94 \%$ \\
\hline Intrauterine contraceptive device & 5 & $4.90 \%$ \\
\hline
\end{tabular}

Majority of ruptured ectopic patients were diagnosed with history, clinical examination and culdocentesis only (77 of $86,89.53 \%$ ), while others ( 9 of $86,10.46 \%$ ) were diagnosed by ultrasonography. Of 16 patients of unruptured ectopic pregnancy 11 patients, $68.75 \%$ had ectopic mass on ultrasound examination and 5 patients, $31.5 \%$ were diagnosed by serial $\beta$ HCG examination.

Table 5: Type of surgical treatment.

\begin{tabular}{|lll|}
\hline & Number & $\%$ \\
\hline Expectant management & 5 & 4.90 \\
\hline Medical management & 11 & 10.78 \\
\hline Salpingectomy & 67 & 65.68 \\
\hline Salpingostomy & 15 & 14.70 \\
\hline Salpingo-oopherectomy & 4 & 3.92 \\
\hline Total & 102 & \\
\hline
\end{tabular}

As shown in Table 5, commonest surgical procedure done was emergency laparotomy followed by salpingectomy (67 of 102, 65.68\%), all of whom had ruptured ectopic pregnancy. Few cases (15 patients, $14.7 \%$ ) underwent conservative surgery. Medical management was done in 11 patients $(10.78 \%)$ and conservative management by serial $\beta$ HCG was done in 5 patients (4.90\%), all of whom had $\beta$ HCG $<1000 \mathrm{mIU} / \mathrm{ml}$. All of these were successful.

36 patients $(35.29 \%)$ had haemoglobin levels $8-10 \mathrm{gm} \%$, followed by 30 patients $(29.4 \%)$ with $10-12 \mathrm{gm} \%$, and 21 patients $(20.58 \%)$ with $12-14$ and 15 patients with $<6 \mathrm{gm} \%$. $51(50 \%)$ patients did not receive any blood transfusion during hospital stay, but 23 patients received one, 3 received two, 14 received three and 11 received $\geq 4$ units of blood transfusion. The mean duration of stay was $6 \pm 2$ days during the study period. Only 5 patients had a post-laparotomy wound infection. There were no cases of maternal mortality in present study.

\section{DISCUSSION}

The incidence of EP found in present study was $1.056 \%$ or 1 in 95 deliveries. It is much higher than incidence reported by authors in the past like Aqueela Ayaz et al reported $0.58 \% \quad(5.8 / 1000$ pregnancies $), 1.04 \%$ by Bangash and Ahmad and $1 \%$ by Waseem. ${ }^{9-11}$ While Lozeau and Potter reported $1.9 \%$ in USA. ${ }^{12}$ The higher rate of ectopic pregnancy found in our study clearly shows the rising incidence of ectopic pregnancy in our environment and world over.

The incidence of EP was found to be highest in 20-24 age group. This was not surprising considering that this is the reproductive age group and has high risk sexual behaviour. Past history of abortion, pelvic inflammatory disease and history of tubal surgery, tubal ligation was found to be the most common risk factors associated with ectopic pregnancy in present study. The increased risk in developed countries has been attributed to pelvic inflammatory disease, smoking in reproductive age women, increased use of assisted reproductive technology and increased awareness of ectopic pregnancy, facilitated by development of early pregnancy units. ${ }^{13}$ Successful management of ectopic pregnancy depends on earlier detection and prompt management. Not only it decreases the morbidity and mortality but also health care cost in terms of repeated visits and hospitalization, radical emergency surgery and future fertility. A high index of suspicion is must for earlier diagnosis. Lower abdominal pain and amenorrhoea were the commonest presenting features in our study.

In present study, majority of patients had ruptured ectopic pregnancy which was diagnosed based on history, physical examination, culdocentesis and supported by pregnancy test. Ultrasound is useful mainly in evaluating patients of suspected EP to localize presence or absence of intrauterine $\mathrm{g} \mathrm{sac}{ }^{6}$ Serial serum $\beta$ HCG was used for diagnosing EP in suspected cases when $g$ sac was not localised by ultrasound.

Commonest site of EP in present study was ampullary region of fallopian tube which has also been reported by other studies. ${ }^{14,15}$ Due to the fact that many EP resolve spontaneous a few cases in present study, were managed on expectant management. Immediate resuscitation with intravenous fluids, blood and emergency laparotomy and salpingectomy is both diagnostic and therapeutic in cases of acute presentation with ruptured EP. ${ }^{5,14}$ Since most cases in present study were ruptured EP salpingectomy was the commonest life-saving surgical procedure performed.

A large number of patients required blood transfusion intraoperatively and postoperatively. This may be attributed to delay in diagnosis and seeking treatment and 
excessive blood loss from the ruptured site. There were no case fatalities during the study period.

\section{CONCLUSION}

Ectopic pregnancy remains a common gynaecological emergency in developing countries and remains a major challenge to subsequent reproductive performance of women worldwide. Its incidence continues to increase due to factors described, it is necessary to device means of early detection to avoid complications. Differential of EP should be kept in mind if a reproductive age woman comes with lower abdominal pain even if amenorrhea is not there. The success rate of medical management was found to be $100 \%$ in appropriately selected cases. Public health awareness, establishment of early pregnancy units and provision of family services will help preventing pelvic inflammatory disease and unwanted pregnancies and therefore EP.

\section{ACKNOWLEDGMENTS}

Authors would like to thank the staff members from Department of Obstetrics and Gynaecology, PGIMS, Rohtak.

\section{Funding: No funding sources}

Conflict of interest: None declared

Ethical approval: The study was approved by the Institutional Ethics Committee

\section{REFERENCES}

1. Chang J, Elam-Evans LD, Berg CJ, Herndon J, Flowers L, Seed KA, et al. Pregnancy-related mortality surveillance-United States, 1991-1999. MMWR Surveill Summ. 2003;52:1-8.

2. Sara HG, Uzelac PS. Early pregnancy risks. In: DeCherney AH, Nathan L, Goodwin MT, Laufer N, editors. Current Diagnosis and Treatment: Obstetrics and Gynecology. 10th ed. Columbus (OH): McGraw-Hill; 2007:259-72.

3. Musa J, Daru PH, Mutihir JT, Ujah IA. Ectopic pregnancy in Jos Northern Nigeria: prevalence and impact on subsequent fertility. Niger J Med. 2009; 18:35-8.

4. Sisti G, Kanninen TT, Di TM, Witkin SS, Spandorfer SD. Autophagy induction by sera from women undergoing an in vitro fertilization cycle varies with subsequent outcome. J Reprod Immunol. 2016;117:1-3.

5. Lin S, Yang R, Chi H, Lian Y, Wang J, Huang S. Increased incidence of ectopic pregnancy after in vitro fertilization in women with decreased ovarian reserve. Oncotarget. 2017;28:14570-75.

6. Ramer I, Kanninen TT, Sisti G, Witkin SS, Spandorfer SD. The serum brain-derived neurotrophic factor concentration prior to initiation of an in vitro fertilization cycle predicts outcome. $\mathbf{J}$ Reprod Immunol. 2016;116:46-9.

7. Mukul LV, Teal SB. Current management of ectopic pregnancy. Obstet Gynecol Clin North Am. 2007; 34: 403-19.

8. Ekele BA. Medical treatment of ectopic pregnancy using parenteral methotrexate. West Afr J Med. 2001;20:181-3.

9. Ayaz A, Emam S, Farooq MM. Clinical course of ectopic pregnancy: A single-center experience. J Hum Reprod Sci. 2013;6:70-3.

10. Bangash N, Ahmad H. A study of 65 cases of ectopic pregnancy in one-year period in military hospital. Pak Armed Forces Med J. 2004;54:205-8.

11. Waseem T. Proportionate morbidity and risk factors of ectopic pregnancy. Ann King Edward Med Univ. 2004;10:298-300.

12. Lozeau AM, Potter B. Diagnosis and management of ectopic pregnancy. Am Fam Physcian. 2005;72: 1707-14.

13. Sivalingam VN, Duncan WC, Kirk E, Shephard LA, Horne AW. Diagnosis and management of ectopic pregnancy. J Fam Plann Reprod Health Care. 2011; 37:231-40.

14. Practice Committee of the American Society of Reproductive Medicine. Medical treatment of ectopic pregnancy. Fertil Steril. 2008;90(Suppl 5):S206-S12.

15. Sotubo O, Aboyeji AP. Ectopic pregnancy in Ilorin, Nigeria: a five-year review. Niger Med Pract. 1994; 27:25-7.

Cite this article as: Malik R, Jain S, Duhan N, Sirohiwal D. Clinical outcomes of ectopic pregnancy. Int J Reprod Contracept Obstet Gynecol 2017;6: 4277-80. 